\title{
CARTELES, PUBLICIDAD Y TERRITORIO: LA CREACIÓN DE LA IDENTIDAD TURÍSTICA EN ESPAÑA (1929-1936)
}

\author{
María Dolores Fernández Poyatos \\ José Ramón Valero Escandell \\ Universidad de Alicante
}

\section{RESUMEN}

El Patronato Nacional de Turismo, desde su fundación en 1928, asumió como una de sus tareas esenciales la promoción turística de España. Para ello, entre otras actividades, editó varias decenas de carteles en distintas lenguas, en los que difundió no sólo la riqueza territorial de nuestro país, sino también una determinada concepción de España que pudiera despertar el interés de potenciales visitantes, es decir, una auténtica identidad turística española.

Analizar desde la óptica publicitaria y la geográfica el conjunto de carteles que han llegado hasta nosotros y establecer los aspectos claves de aquella promoción de nuestro país es el objetivo de este artículo.

Palabras clave: cartel, publicidad, Patronato Nacional de Turismo, identidad territorial, identidad turística, promoción turística, eslogan.

Posters, advertising and territory: the creation of the touristic identity in Spain

\begin{abstract}
Since its foundation in 1928, the Patronato Nacional de Turimo assumed, as one of its essential duties, the touristic promotion of Spain. For that, among other activities, they edited several posters in different languages in which, not only the richness of our country was issued, but a whole conception of Spain that could awake interest of potential visitors, that is to say, a unique and authentic touristic identity of Spain.
\end{abstract}

Recibido: 8 de septiembre de 2013

Devuelto para su revisión: 4 de febrero de 2014

Aceptado: 4 de julio de 2014

Instituto Universitario de Estudios Turísticos. Universidad de Alicante. Apartado 99. 03080 ALICANTE (España).E-mail: dolores.fernandez@ua.es,jose.valero@ua.es 
This article has the objective of analyzing the advertising and geographical perspective of the group of posters that came to us and establishing the key aspects of that promotion of our country.

Key words: poster, advertising, Patronato Nacional de Turismo, territorial identity, touristic identity, touristic promotion, slogan.

\section{INTRODUCCIÓN}

Los viejos carteles poseen, sin duda, un atractivo excepcional, en buena media por esa mezcla de ingenuidad y de enlace con los rasgos esenciales de la identidad de los distintos lugares. Hoy, convertidos en un icono de una época añorada, en un recuerdo nostálgico de muchos de los lugares y objetos más bellos del planeta, se les reconoce un indudable valor como expresión artística y como documento capaz de sintetizar una época; por eso, hace ya tiempo que historiadores y publicitarios han puesto su atención en analizarlos minuciosamente y caracterizarlos en su contexto preciso.

Los carteles turísticos, desde sus primeros ejemplos - mucho más que en la actualidad, porque la competencia de otros medios de comunicación es extremadamente fuerte-, colaboraron con eficacia en la forja de una imagen internacional de los distintos países, real o adaptada, pero tan sólidamente establecida que han demostrado una enorme capacidad de resistencia con el paso de los años. En España, se ha dicho con razón que el estudio histórico de los orígenes de la actividad turística ha sido escaso hasta fechas muy recientes (Moreno, 2012: 114), pues la atención estaba centrada sobre el desarrollo del turismo litoral mediterráneo e insular a partir de los años sesenta y las transformaciones socioeconómicas que ello supuso para el conjunto del país. Con ello, el estudio de los carteles turísticos del primer tercio del siglo XX se ha focalizado, sobre todo, en sus aspectos artísticos y publicitarios.

Sin embargo, el objetivo esencial de aquellos carteles de promoción turística era la transmisión de los valores de un territorio, contribuyendo con ello a establecer lo que podríamos denominar una identidad turística española en el ámbito internacional. Precisar qué imagen territorial se pretendió transmitir en aquellos carteles iniciales del turismo español y si se fue capaz de establecer de manera más o menos sistemática una identidad turística «nacional» es el objetivo del presente artículo.

Es necesario establecer antes unas precisiones conceptuales en torno a la noción de territorio, y también delimitar qué podríamos entender como identidad turística. El término territorio, esencial para los geógrafos aunque no sólo para ellos, posee un marcado carácter polisémico ligado a un paisaje - preexistente o cultural-, a los elementos físicos y humanos de un determinado lugar, a las relaciones entre la sociedad y el medio que habita y a las que se establecen entre sus distintos aspectos demográficos, económicos o sociales; su significado es tan variado que para un geógrafo físico puede entenderse casi como sinónimo de la superficie terrestre y para un geógrafo político vincularse al concepto de Estado. En buena medida, el concepto de territorio que pretende mostrarse a través de los diferentes carteles que estudiaremos aúna casi todas estas interpretaciones. 
Por otra parte, es evidente que la identidad cultural de cualquier lugar - a distintas escalas - estaría cimentada sobre unos valores mayoritariamente compartidos, unos símbolos en los que la comunidad tiende a reconocerse, unas tradiciones que aprecia y trata de conservar y unos comportamientos en los que transcurre su vida cotidiana. Por supuesto, desde cualquier institución política o grupo de poder $-\mathrm{y}$ aquí estudiaremos carteles surgidos desde la esencia misma del aparato estatal - se trata de caracterizar la identidad a partir de sus propios intereses y conveniencias. La complejidad de toda sociedad establece una realidad más poliédrica: la caracterización identitaria de un territorio acaba siendo pluriforme, en función de los distintos grupos que interactúan en él, pero siempre privilegiando aquellos rasgos que convienen a quienes tienen mayor capacidad o instrumentos más eficaces para imponer sus preferencias. En la promoción turística de cualquier destino, se trata de destacar aquellos rasgos identitarios en los que se reconocen mejor aquellos grupos social o políticamente predominantes, siempre y cuando se estime que pueden ser positivamente valorados por la demanda turística potencial a la que esperan seducir. A partir de la confluencia entre la identidad cultural en que se reconoce la sociedad de un territorio y el deseo o la necesidad de sintetizarla en aquellos aspectos que resulten atractivos a los potenciales visitantes, podríamos delimitar el concepto de identidad turística.

Aunque existen carteles turísticos desde la aparición de las primeras entidades locales de promoción turística - como las de Palma de Mallorca o San Sebastian - y algún ejemplo aislado de cartel relacionado con España en su conjunto, los carteles que vamos a analizar son los editados por el Patronato Nacional de Turismo entre 1929 y 1936 (incluyendo también aquellos surgidos en Cataluña durante el funcionamiento del gobierno autónomo), a partir de las fuentes del Centro de Documentación Turística de España del Instituto de Estudios Turísticos, tanto a partir de su portal en internet ${ }^{1}$ como del catálogo editado en 2005 . No obstante, el análisis se ha completado con una concienzuda búsqueda bibliográfica y en red, que nos ha permitido rescatar algún otro cartel suplementario a aquellos que aparecen reflejados en ambas publicaciones, además de algunas variantes en lenguas diferentes y algunos dibujos que pudieron servir como base para otros carteles, a veces dibujos adquiridos por el Patronato sin que tengamos constancia cierta de que llegaran a editarse. Estamos, pues, ante una base documental que podríamos calificar como todavía en construcción.

A partir de esta fuente básica, se ha intentado realizar un análisis desde dos puntos de vista, que pueden ser eficazmente complementarios, el publicitario y el geográfico, completado con un análisis bibliográfico y de carácter legislativo que permita encuadrarlo en el contexto histórico que les dio vida. Así, a partir de aquellos primeros carteles de promoción turística de España de manera sistemática hemos buscado delimitar cómo se construyó el concepto de identidad turística española y cuáles fueron las características expresivas y los recursos territoriales de los que se sirvió aquel grupo variopinto de artistas que protagonizó un momento de excepcional brillantez en el arte publicitario español, muchos de ellos protagonistas también de la cartelería de nuestra Guerra Civil, tan diferente en temática y contexto histórico pero, sin duda alguna, de una calidad artística también excepcional.

1 La consulta en Internet puede realizarse en la siguiente página: http://www.iet.tourspain.es/es-es/documentacionturistica/consultabddocumental/espanol/catalogos/paginas/catalogosturisticos.aspx. El catálogo aparece citado en bibliografía. 


\section{LA PUBLICIDAD TURÍSTICA EN ESPAÑA. EL CARTEL TURÍSTICO}

La actividad publicitaria en España se inició a finales del siglo XIX y se consolidó en el primer tercio del siglo XX, acompañando el proceso de modernización de la sociedad y la economía española. Fueron varios los hechos que concurrieron (Andrés, 2002: 19-20): el nacimiento de un nuevo concepto de publicidad, los primeros profesionales y agencias técnicas, los primeros cursos y manuales sobre la materia... Prácticamente todo converge en Prat Gaballí, pionero de la publicidad española, y en el grupo que trabajó en torno a su magisterio: el Publi-Club catalán. Su labor fue sobresaliente en la forma de concebir la publicidad que acabaría por imponerse.

Los publicitarios españoles y extranjeros idearon campañas en el primer tercio del siglo XX conforme a un método que los distanciaba de la publicidad del momento. Se trataba ahora de una publicidad racional, ordenada en cuanto planificada y con una finalidad clara; una publicidad donde «el elemento estrictamente decorativo, cuyo único objeto fuese embellecer, carecería por completo de fuerza publicitaria» (Prat, 1934: 171).

Las manifestaciones más numerosas de esta actividad se hallan en periódicos y prensa ilustrada de la época, siendo esta última la que ofrece, sobre todo a partir de 1920, una publicidad de ideación moderna y actual, donde se aprecia que los sectores con más peso fueron, de mayor a menor, el de las medicinas patentadas, hogar, consumo suntuario y belleza (Fernández Poyatos, 2011: 109).

En España, aunque Goya ya había elaborado con técnica litográfica su extraordinaria serie sobre temas taurinos (Gubern, 1997:9-18), el primer cartel con fines comerciales fue el realizado por el dibujante satírico Francisco Ortego y Vereda en la década de 1870 para los chocolates y dulces Matías López (Bori y Gardó, 1928: 57). La proliferación de carteles a finales del siglo XIX los muestra como el medio idóneo (y complementario a la publicidad en prensa) para anunciar mercancías; no en vano, los industriales, sobre todo catalanes, organizaron numerosos concursos para seleccionar los que mejor servían a la promoción de sus productos; gracias a ellos, el cartel consiguió el impulso decisivo que le llevó a ser la gran forma publicitaria de los años que cierran el siglo, así como de los que inauguran el ulterior. Se hace obligado recordar el primer concurso convocado en 1898 por el industrial Vicente Bosch para Anís del Mono, al que concurrieron célebres artistas del momento como Ramón Casas (ganador y autor del celebérrimo cartel «Mona y mono»), Alexandre de Riquer y Roig i Valentí.

La publicidad turística apenas tuvo presencia en la prensa periódica, donde esporádicamente se insertaban anuncios de hoteles, compañías de transporte naviero y agencias de viajes. El turismo, como actividad económica y social, apenas era relevante en nuestro país; y ello a pesar de que en 1905 se creó la Comisión Nacional, dentro del Ministerio de Fomento, primer organismo estatal ligado al turismo, cuyo cometido fue entre otros el de «Publicar y difundir en el extranjero [...] datos históricos, descripciones de nuestros monumentos y cuanto se considere útil para la mayor apreciación de las bellezas artísticas y naturales, para el conocimiento de nuestra historia y para despertar la curiosidad de los extranjeros» (Gaceta de Madrid del 7 de octubre de 1905). Aunque el Ministerio incluyó en su próximo presupuesto una cantidad «á fin de atender a la impresión y propaganda» de sus trabajos de difusión (Art. $\left.4^{\circ}\right)$, el dinero nunca llegó y su labor se redujo a la publicación de algunos impresos (Cal, 1997: 127). 
A la Comisión Nacional Permanente le sucedió la Comisaria Regia del Turismo (1911-1928) que también se propuso divulgar la cultura artística del país mediante guías y catálogos (Real decreto del 19 de junio de 1911); sin embargo, y de nuevo, la carencia de presupuestos lo impidió. Tras 17 años de actividad monopolística de su primer y único comisario, el marqués de la Vega-Inclán, se disolvió y fue sustituida por el Patronato Nacional de Turismo, que supuso el inicio de la mayor actividad comunicativa que hasta la fecha había desarrollado un organismo público turístico en España.

Aunque el cartel español alcanzó su esplendor ligado al desarrollo de la publicidad en el primer tercio del siglo XX, cuando sus posibilidades expresivas y su notoriedad llevaron a numerosos anunciantes - públicos y privados - a elegirlo como fórmula de comercialización y popularización de sus productos y servicios, la promoción turística española de ámbito estatal no recurrió a él de manera sistemática hasta la puesta en marcha del Patronato Nacional de Turismo en 1928, aunque existen carteles previos editados por el Estado, como el famoso «Sunny Spain» de 1914, al que después nos referiremos. Sí lo habían hecho, de forma más o menos discontinua y asistemática, algunas agencias de viajes pioneras - Viajes Marsans o la Compañía Española de Turismo, que contó con el pintor Segrelles entre sus colaboradores estables-, varias compañías de ferrocarriles y de navegación (Bayón, 1999: 31) e instituciones de ámbito local, como los sindicatos locales de iniciativas surgidos en la primera década del siglo - con nombres más o menos similares - en algunas de las ciudades más dinámicas del país como Barcelona, San Sebastián o Palma de Mallorca, ya claramente comprometidas con el fomento del turismo en sus territorios.

\section{EL PATRONATO NACIONAL DE TURISMO: EL CARTEL COMO PIEZA BÁSICA DE LA PROMOCIÓN TURÍSTICA ESPAÑOLA}

El Patronato Nacional de Turismo (en adelante, PNT) fue creado por Real decreto del 25 de abril de 1928 (publicado en la Gaceta de Madrid del día siguiente), en sustitución de la Comisaría Regia de Turismo, surgida en 1911. Su función esencial era afrontar en condiciones razonables de éxito el reto turístico que se preveía para las ya cercanas exposiciones de Barcelona -Internacional-y de Sevilla -Iberoamericana- para cuya inauguración quedaba un año. El conde Güell había convencido al dictador Primo de Rivera de que para ello era necesario constituir un organismo más funcional y de estructura más moderna que la vieja Comisaría Regia presidida por el marqués de VegaInclán. Por supuesto, el conde Güell, propietario naviero, presidiría el órgano rector, un Comité Directivo de diez miembros, en el que era absoluto el predominio de lo que se ha llamado «lobby catalán» (Moreno, 2007:120), constituido también por Marsans y los propietarios de la cadena hotelera HUSA; asimismo, formaron parte del mismo algunas personalidades menos conocidas que alcanzarían marcado protagonismo durante el primer franquismo (caso de Luis Bolín o Soriano Frade). La estructura de dicho comité contaba con la presencia de los cinco subdelegados de zona en que se había estructurado el nuevo organismo.

El incremento de sus funciones respecto a la anterior Comisaría Regia es bien patente comparando simplemente los decretos fundacionales de ambos organismos - el del 
organismo procedente, publicado el 20 de junio de 1911-, aunque las referencias a la continuidad de la misión y la transferencia de algunas obligaciones son bien patentes. Se ha destacado que, por primera vez en España, la Administración actuó sobre un amplio abanico de actividades estrechamente relacionadas con el turismo (Pellejero, 2002: 238). Entre las numerosas funciones que el decreto otorga al PNT (véase el artículo segundo del real decreto fundacional), se encuentran desde el estímulo al desarrollo de la industria hostelera hasta la fundación de centros o agencias de turismo allí donde no existían, pasando por la creación de escuelas de turismo o cualquier iniciativa económica, social, deportiva o cultural que pudiera mejorar el sector en nuestro país, buscando la colaboración de un amplio abanico de entidades socioeconómicas de todo tipo. Se plantea, además, una financiación independiente para el organismo, que provendría de una amplia participación en el Seguro Obligatorio de Viajeros transportados por ferrocarril o navegación marítima e incluso del transporte de ganado; esta financiación permitió al organismo un funcionamiento tan autónomo que, especialmente en un momento de fuerte enfrentamiento entre la monarquía y las emergentes formaciones republicanas, fue acusado de incontrolado y puesto al servicio de fines políticos ajenos a su cometido.

Dado que su existencia se prolongó desde la época final de la dictadura de Primo de Rivera hasta la Guerra Civil, el PNT vivió dos fases bien diferentes, perfectamente descritas por Moreno (2007: 117-129). No sólo el cambio político, sino también la crisis económica de 1929, que redujo fuertemente los ingresos procedentes del seguro de viajeros, contribuyeron a una evolución que incluso llegó a la desaparición temporal en los primeros días de la II República y su sustitución por una Dirección General de Turismo, que sólo duró unos meses. El PNT republicano simplificó el organigrama directivo y disminuyó fuertemente su autonomía, redujo las oficinas exteriores y provinciales y, por lo que respecta a este artículo, aminoró el ritmo de edición de nuevos carteles, aprovechando el esfuerzo realizado en la época de las grandes exposiciones.

Otra modificación de calado fue la coexistencia con un organismo autónomo, la Oficina de Turisme de Catalunya, surgida en 1932 a partir del estatuto de autogobierno catalán; el PNT colaboró con el mismo y realizó la difusión exterior de los materiales editados por este, además de transferirle sus oficinas y personal. La nueva entidad catalana, como sucediese en los primeros momentos del PNT aunque a una escala menor, también impulsó la edición de carteles sobre sus propias comarcas.

El PNT contó desde el primer momento con una fuerte ramificación geográfica, visible desde el momento en que se estructuró inicialmente a partir de cinco subdirecciones regionales -Central, Cantábrica, Aragón-Cataluña-Baleares, Levante y Andalucía-CanariasMarruecos -, a la que se sumó pronto otra más, la Occidental. En el exterior contó con oficinas en París, Londres, Roma, Munich, Gibraltar, Nueva York y Buenos Aires, y en España con casi medio centenar de oficinas de información (Bayón, 1999: 34). Además de eso, debía ocuparse de todo el patrimonio gestionado por la anterior Comisaría Regia y fomentar el desarrollo de una red de Paradores - el primero, Gredos, ya había comenzado a construirse con anterioridad - y otras construcciones complementarias, que irían desde albergues de carretera y montaña - que la República impulsó como aspecto clave - a hosterías o un campo de golf en Málaga. Esta organización geográfica hubo de influir, como veremos, en la política de edición de cartelería. 
Pese a todo lo anterior, es cierto que el Estado ya había acometido de alguna manera buena parte de las funciones encomendadas al PNT. Si existió una política de construcciones, también la Comisaría Regia había asumido la recuperación de algunos monumentos como la Casa del Greco o los Jardines del Alcázar, e incluso el saneamiento y regeneración social del barrio sevillano de Santa Cruz (Fernández Fuster, 1991: 281), además de iniciar el primer parador. Dejando al lado la nueva filosofía de gestión, cabría destacar que sólo la elaboración de estadísticas específicas o el reglamento sobre guías e intérpretes supusieron innovaciones notables.

Ahora bien, fue en la promoción turística realizada previamente de manera muy esporádica, por ejemplo en la malograda Exposición universal de Londres de 1914, donde el nuevo PNT iba a encontrar la esencia de su propia función. El citado art. 2 del Real decreto de creación ya la destaca como la primera de sus funciones: «divulgar en todos sus aspectos el conocimiento de España, fomentando para ello la publicacíon de guías, catálogos, anuncios, itinerarios, etc., dentro y fuera de nuestra patria, ya directamente o contratando en su totalidad o en parte este importante servicio».

La importancia que el turismo extranjero podía reportar a nuestro país quedó registrada en el apartado e) que perseguía la promoción y apoyo de la propaganda mediante la organización de centros de información y viajes en otros países. Era imprescindible atraer al turismo exterior, pues en España esta actividad estaba reservada a una elite que no garantizaba por sí sola una configuración moderna del sector.

El PNT tuvo tres delegaciones, siendo una de ellas la denominada Delegación de propaganda, cuyo cometido era el de redactar «las publicaciones divulgadoras de España desde el punto de vista turístico; procurar esta divulgación en revistas españolas y extranjeras y prensa de todos los países; disponer conferencias y certámenes para dar a conocer cuanto España encierra de atrayente para el turista; crear a estos fines los organismos necesarios en el extranjero; fomentar la educación artística y la formación de guías aptos».

El PNT emprendió acciones de promoción muy notables que hubieran permitido consolidar una estrategia de comunicación turística sólida si los problemas económicos y los conflictos políticos y sociales del país no hubieran alcanzado el protagonismo que desembocó en la Guerra Civil. Su año más fructífero fue 1929; contó con ingresos y desarrolló campañas publicitarias fuera de España y en las exposiciones universales de Sevilla y Barcelona. El propósito de Güell de dar a conocer el país en el extranjero se plasmó en diversas actuaciones, entre las que destacamos la invitación a periodistas extranjeros para visitar España (press trips) y la ideación de un plan general de propaganda turística mundial (Moreno 2010: 106), cuyo presupuesto se cifró en cuatro millones de pesetas.

La invitación a periodistas es una acción muy utilizada en la actualidad; son los press trips y fam trips, también llamados viajes de familiarización, que se planifican para que los profesionales del sector turístico, responsables de recomendar lugares turísticos, entren en contacto directo con el destino. Se trata de viajes organizados con mayoristas (prensa, agencias, operadores turísticos...) de los principales países emisores. En el caso que nos ocupa, se trataría del primer testimonio de su uso.

El plan de propaganda turística mundial consideró medios y acciones tanto actuales como tradicionales: fotografía, conferencias, cinematógrafo, folletos, guías, postales, 
sellos y carteles. De esta ingente labor, desarrollada sobre todo entre 1929 y 1930 , quedó el legado de los carteles del Patronato, a cargo de dibujantes y pintores sobresalientes de la época que fueron fundamentalmente soportes con un principal sentido comercial: el de mostrar los recursos culturales y paisajísticos más sobresalientes del país a fin de seducir a un target interesado en conocerlos y disfrutarlos, y que son el objeto de nuestra investigación.

Los carteles que editó el PNT tuvieron dos épocas diferenciadas, que se corresponden con las del organismo (Herrero, 2012: 184): el Patronato monárquico (1928-1931) y el Patronato republicano (1931-1939). La primera representa los momentos más fructíferos en cuanto a la preparación de campañas de promoción y edición de carteles, azuzada por la necesidad de presentar una imagen variada y multiforme del país, tanto a los visitantes potenciales de las exposiciones de Sevilla y Barcelona, como a la propia población autóctona, en un intento de prestigiar la propia realidad nacional. La segunda, con una producción mucho menor, en función tanto de la disponibilidad de los carteles previamente editados como de la reducción de las posibilidades del organismo oficial; durante los años bélicos sólo se editaron cuatro carteles, en 1937, de clara propaganda antifascista, con el objetivo de acusar al llamado bando nacional de la destrucción del patrimonio artístico español.

El primero de los carteles, editado en Francia en colaboración con las compañías ferroviarias españolas y francesas, sólo pretendía comunicar la celebración de las exposiciones de Sevilla y Barcelona. Los siguientes carteles corresponden a la campaña preparada para la Exposición Iberoamericana de Sevilla en 1929; a tal efecto, se encargó a dibujantes y pintores españoles o avecindados aquí la realización de carteles de numerosas provincias españolas, cada uno de los cuales tenía garantizada la percepción de un mínimo de quinientas pesetas. Los carteles, aunque de estilo libre, debían observar determinadas pautas: disposición vertical, unas dimensiones uniformes de $1.25 \mathrm{~m}$. x $1.00 \mathrm{~m}$ y tener como protagonistas las bellezas monumentales o naturales de cada territorio, limitando el protagonismo de las figuras. En los 25 centímetros inferiores se dibujaría en letra grande el título de la provincia y en caracteres más pequeños, el nombre del Patronato Nacional del Turismo, cuyo emblema figuraría con un diámetro de 15 centímetros. Sabemos que algunos dibujantes rechazaron el encargo por diversos motivos, desde la disconformidad con la provincia asignada al precio estipulado; Segrelles, por ejemplo, renunció a participar por ser dibujante de la Compañía Española de Turismo (Herrero, 2012: 181-188).

De los cincuenta y un carteles presentados, fueron premiados con mil pesetas los correspondientes a Sevilla (Juan Miguel Sánchez), Baleares (Josep Renau), Barcelona (Federico Ribas), Córdoba (Sáez de Tejada) y Málaga (Ricardo Verdugo); además, recibieron mención los de Ávila (Penagos), Coruña (Castelao), Palencia (Téllez), Toledo (Baldrich) y Vizcaya (Colde Guezala). Es revelador comprobar que entre los citados estaban algunos de los más representativos cartelistas vinculados a nuestra posterior guerra civil, tanto en el bando nacional (Sáez de Tejada), como en las distintas tendencias del republicanismo (desde el comunista Renau al nacionalista Castelao). No todos los dibujos presentados a la exposición fueron reproducidos en cartel. Es interesante señalar que una de las causas por las que estos últimos no fueron premiados fue la de no reunir las condiciones estimadas para un cartel de esta índole, pues no sólo debía ser una bella estampa o un ilustración de folleto. La publicidad decorativa ya no servía; el Patronato buscaba, antes 
que la belleza artística, piezas publicitarias que transmitieran la ventaja del producto a fin de que el potencial turista conociera bien el beneficio que iba a obtener: arte milenario, modernidad, clima amable, romanticismo, exotismo, misterio... El Patronato se mostró aquí como un anunciante moderno y actual, para el que primaba la finalidad comercial de un mensaje publicitario.

Estos primeros carteles oficiales, editados en cuatro idiomas - alemán, español, francés e inglés - por un servicio de publicaciones presidido por el poeta Pedro Salinas constituyen la edad de oro del cartel de turismo español. Económicamente, la retribución a los artista fue sólo unas migajas de una generosa política de promoción turística para la que se destinaron cuatro millones de pesetas y que incluía, además, publicidad en prensa española y extranjera, cinematógrafo, conferencias, fotografía y distribución (Moreno, 2010: 122).

En los años posteriores fueron editados un número indeterminado de nuevos carteles, nacidos tanto del ingenio de alguno de los dibujantes seleccionados para la exposición de Sevilla como de otros que se fueron incorporando posteriormente y, especialmente, de algunos afamados fotógrafos del momento - Wunderlich, Andrada, Lladó... - , porque pronto aparecieron también los carteles con motivos fotográficos. Durante los años republicanos, se publicaron en la Gaceta de Madrid algunas convocatorias de concurso para adquirir dibujos sobre temáticas concretas para el PNT, con premios de mil o dos mil pesetas. En la Gaceta del 12 de mayo de 1935 se publicó otro concurso para premiar un máximo de cinco dibujos a cuatro tintas en los que debían exaltarse los atractivos climáticos de España en su aspecto de país meridional y luminoso, con un único título: Visit Sunny Spain. Lema en inglés y referencia a un país soleado: una concepción absolutamente precursora del que en los años sesenta sería el concepto turístico de la España del sol y playa.

No obstante, conviene volver a recordar que la relación de carteles ligados al PNT está lejos de poderse considerar definitiva. Por ejemplo, la Gaceta del 27 de junio de 1932 recoge el fallo del concurso para la adquisición de uno sobre el itinerario «Marroc-France a travers 1’Espagne» y de otro sobre las Islas Canarias. Sabemos que Antonio Moliné ganó el premio con su dibujo sobre Canarias, y poseemos el cartel publicado posteriormente; sin embargo, José Espert ganó el concurso sobre el itinerio y en la Gaceta está publicado que se acordaría convenir con él la adquisición de otro sobre Canarias, sin que tengamos constancia de ninguno de ellos. En algunos casos, existe evidencia de carteles sobre Alicante o las Rías Bajas que no figuran entre las publicaciones antes indicadas y que son accesibles sin excesivas dificultades a través de internet. Tampoco resulta fácil delimitar el número de carteles basados en fotografías realmente editados, pues algunas de estas fotografías aparecen también -o a veces únicamente- en algunos de los múltiples folletos publicados sobre determinados territorios. Por ejemplo, entre los no publicados en el catálogo del Instituto de Estudios Turísticos se encuentra el que contiene el eslogan Spain is different, con foto de Andrada (imagen 1), al que se refiere con fina ironía R.E. (probablemente, Rafael de Eulate) en el artículo «El turismo, artículo de primera necesidad», firmado el 5 de enero de 1935 en La Vanguardia barcelonesa. A esta relación imprecisa habría que añadir, además, los emanados de la Oficina de Turisme de Catalunya, que el PNT también distribuía, entre los que ya se encuentra un cartel de Morell - el gran cartelista de los años cuarenta - relativo a Sitges (imagen 2). 
De todas formas, tampoco conviene idealizar demasiado la influencia inmediata de aquellos carteles. En 1979, el financiero Aguirre Gonzalo recordaba en El País un artículo escrito por él en torno a 1931, en el que decía «He estado este invierno en la Costa Azul, y no había propaganda alguna de España al lado de la enorme de todos los países del mundo. Lo mismo me ocurrió en Suiza hace dos años. Y en el mejor hotel de Roma (Plazza) no habla nada español, y eso que tenían revistas suecas, griegas y hasta japonesas. [...] Sé que existe el Patronato Nacional de Turismo. Desconozco su funcionamiento, pero creo que no se ha preocupado de nuestra propaganda en el extranjero».

\section{LOS MENSAJES DEL CARTEL}

El cartel es una unidad de comunicación formada por dos elementos -imagen y texto - y como tal ha de ser entendido desde su ideación. La primera es la reproducción icónica del producto; la segunda, la explicación escrita. Como soporte de comunicación publicitaria que es, persigue el «intercambio de ideas, de palabras, o de otras señales (en un sentido amplio), que tienden a producir un determinado comportamiento 'buscado'; y para originar una conducta se exige que sea percibida y correctamente interpretada, por lo que debe constituir un diálogo entre el emisor y el receptor» (Sanz de la Tajada, 1974: 10). Ello implica que, para persuadir y ser persuadidos, emisor y receptor han de compartir un código y un contexto sociocultural.

Como manifiesto publicitario² (según la terminología de Péninou, 1976: 259-308), el cartel puede estar formado por una pluralidad de mensajes distintos: el de pertenencia al género, el de referencia al emisor, el lingüístico, el icónico y el de inferencia. Los dos primeros pertenecen al plano de la identidad; los dos siguientes, al de la denotación y el último al plano de la connotación.

El cartel, en sí mismo, posee sus propias marcas de género, que son aquellas que lo distinguen de otros medios y soportes similares: sus dimensiones - que en los emitidos por el PNT fueron ligeramente variables en cada momento-, su composición, los colores, la tipografía.

La referencia al emisor es hoy bastante inusual; sin embargo, en la década de los veinte se constata su creciente inclusión, debido a la necesidad de sus autores de presentarse ante aquéllos que puedan estar interesados - anunciantes, directores de prensaen conocer la procedencia de los anuncios (Péninou, 1976: 63). Siempre ha ocupado un lugar discreto y marginal: en tipografía de tipo pequeño, generalmente en los márgenes o en la parte inferior, lo encontramos en los carteles del Patronato Nacional de Turismo en las firmas de Renau, Ribas, Penagos, Castelao... La rúbrica de los autores es una forma casi privativa del cartel.

En cuanto al mensaje de inferencia estamos ante un mensaje abstracto, consistente en lo inteligible del manifiesto, y que coincide con el significado de intención (calidad, belleza, excelencia...), siendo al mismo tiempo conjetural y plurívoco. Se trata de un men-

2 Para Péninou, asimilar el concepto de mensaje publicitario al de anuncio, es limitar demasiado su contenido, ya que en un anuncio existen varios mensajes. El término manifiesto publicitario es definido como «El soporte de esa sustancia informativa compleja que es el anuncio, el cartel, la valla publicitaria, el spot televisivo» (1976: 43). 
saje hipotético, y las posibilidades de interpretación de los signos serán tales que raramente la relación significante-significado resultará única (Feliu, 1982: 170).

De los elementos que conforman la componente textual de un anuncio, el eslogan es primordial. El término fue adoptado por la publicidad en la Francia de 1927, donde se le llamaría «la gran vedette de la publicidad», institucionalizándose con el apoyo masivo de la publicidad estadounidense de los años treinta (Ferrer, 1994). Definido como «expresión concisa o ingeniosa que se emplea en un anuncio o en su cierre» (Alcaraz, Hugues y Campos, 1999: 300), el eslogan es una frase hecha, causal u organizada que el uso profesional ha elevado a una categoría relevante, y sin la que no es posible concebir un mensaje publicitario.

Una primera cuestión que se debate en torno a su significado es la de su definición: texto, fórmula, expresión, aforismo, palabra, frase; de nítidas características: breve, sugestivo, cuya función es la de resumir y hacer recordable el anuncio; «es la expresión lingüística económica, significativa, brillante, perdurable, exclusiva y eficiente de una estrategia de comunicación empresarial, política o institucional» (Garrido, 2000: 70).

Aunque otros elementos de la componente textual sean también relevantes para la redacción publicitaria, tienen un lugar secundario en el cartel, donde la síntesis, la simplificación de contenido y la sencillez son ineludibles. El eslogan es por ello la estructura más acorde a estos requisitos; y todo sin olvidar que gran parte de la efectividad en el cartel descansa en el poder de su imagen, siendo el mensaje verbal una información complementaria (Coronado 2011: 42), pero no menos importante. Así, las frases hechas - eslóganes y título, en su sentido más ortodoxo, o no- que rubrican los carteles del Patronato Nacional de Turismo quedaron fuera de las normas del concurso de 1929 para la Exposición de Sevilla; por el contrario, sí se incluyó la obligatoriedad en cuanto al asunto y diseño de la imagen: bellezas monumentales o naturales de cada región y limitación de figuras.

Se han revisado las tres grandes formas de composición en los carteles: 1) Los que contienen texto e imagen, 2) Los que contienen solo imagen y 3) Los exclusivamente textuales (Alcocer, 1991: 11). Los primeros son los más habituales; los segundos se utilizan cuando el producto es conocido y los terceros, cuando el fin informativo es el más buscado. Se persigue en este estudio conocer la forma predominante en los carteles del Patronato.

En segundo lugar, se ha revisado el mensaje lingüístico de los carteles editados en varias lenguas. El objetivo ha sido el de comprobar si variaban los mensajes en función del idioma para constatar, o no, su adaptación a los diferentes mercados turísticos.

En lo referente al eslogan publicitario, para la identificación de los elementos de análisis, se han seguido los estudios más relevantes (Reboul, 1978; Klenosky y Gitelson, 1997; Garrido, 2000; Peña, 2001; Pike, 2004; Ortega y Rauld, 2006; Donaire y Galí, 2012; Garrido, Rey y Ramos, 2012). De entre dichos elementos, se ha optado por examinar los siguientes: el número de palabras, la identificación de la marca en el eslogan, la estructura nominal/verbal, la utilización de palabras llenas/vacías, la presencia de destino y productos turístico y la presencia de atributos predominantes (ventaja del producto/beneficio para el consumidor).

En cuanto a la forma de composición, casi todos los carteles del Patronato Nacional de Turismo contienen texto e imagen; ninguno es exclusivamente textual y dos -ambos de 1930- carecen de eslogan: el del Parador de Gredos y el del Parador de Oropesa, que 
tampoco tiene título. El resto presenta la estructura más habitual en el cartel: un mensaje textual compuesto por título y pie y un mensaje icónico formado por una ilustración.

La mayoría de carteles analizados pertenecen a los años 1929 y 1930, siendo un grupo notable de ellos reimpresiones de los carteles de 1929, bien de años posteriores, bien del mismo año de 1929, pero en lenguas distintas al castellano. A principios de la República, se acuñó sobre el logotipo coronado una inscripción de República Española para seguir utilizando carteles anteriores. En la mayoría de los carteles repetidos, varía el eslogan al cambiar el idioma. Según el mercado emisor al que se destinaban, los carteles ofrecían ventajas y beneficios turísticos distintos; lo que sirve para afirmar que se estaba considerando el público al que se dirigía, tal y como se hace en la actual planificación publicitaria.

Los carteles de 1929 que se repiten en 1930 son los de Córdoba, Toledo, León, Tenerife y uno sobre el conjunto de España. Es habitual la práctica de conservar la componente icónica de un cartel y cambiar el destino turístico, modificando el titular y el eslogan. Así, por ejemplo, el cartel de Córdoba -Cour des Caliphes - de 1929 se reutilizó un año más tarde para el destino España: «Le confort de l'Éuropel La luxuriance de l'Afriquel Vous attendent en Espagne». Lo mismo sucedió con León — «Poema de luz y piedra. Tumba de reyes»-, que sirvió para promocionar el país: «Un voyage en Espagne est un date dans la vie».

El conjunto de carteles que se editaron el mismo año de 1929 en otras lenguas es profuso: Cádiz, Málaga, Córdoba, Ávila, Huelva, Madrid, Roncesvalles, Santander, Sevilla, Tarragona y Valladolid...Tal vez lo fueran todos, aunque hoy no conservemos ejemplares. Las lenguas utilizadas fueron francés, inglés y alemán. En casi todos, el ejemplar en español corresponde a la estructura originaria de su diseño: se inician con el titular Patronato Nacional de Turismo, una imagen central y un eslogan en la parte inferior encabezado por el nombre del destino. Cuando se difundían en una lengua distinta a la española, se mantenía la imagen y se introducían cambios en el texto: el titular se reemplazaba con la exhortación «Visitad España» (Visit Spain, Visitez l'Espagne, Spanien) y los eslóganes modificaban su contenido de un idioma a otro. De nuevo, la búsqueda de un target específico.

En lo referente al número de palabras del eslogan, predomina el eslogan breve (mayor facilidad de recuerdo): la mayoría de ellos - 46 de los 75 eslóganes analizados - utilizan entre tres y seis palabras. También había carteles con eslóganes más largos: 19 cuentan entre 7 y 10 palabras; otros 10 superan la decena de palabras. A partir de 1929 se observa una evolución hacia una mayor extensión de palabras.

La marca puede estar fuera del eslogan o integrada en él (al principio, en medio o al final). En nuestro estudio, y a excepción de «La imperial Toledo» (dentro y al final) siempre está al principio, independientemente de su idioma: «Ávila. La mística ciudad amurallada», «Bilbao. The Abra Beaches», «Córdoba. Cour des Caliphes»... Asimismo, la estructura predominante en los eslóganes es claramente nominal; en casi todos, el verbo está elidido, prevaleciendo las palabras de significado pleno (sustantivos y adjetivos) y de gran significación, frente a las vacías (pronombres, adverbios. conjunciones, artículos, preposiciones); su organización es, así mismo, sencilla: «Spain. Glorious Spring»; «Tenerife. Las islas afortunadas» 
Se confirma que nos encontramos en las primeras etapas de la comunicación comercial publicitaria y también ante una característica esencial como es la de la sencillez y simplificación formal: el cartel comercial es, antes que arte, comunicación, «de pretensión más racional [...] es sólo un medio para un fin» (Gubern, 1997: 191).

\section{EL TERRITORIO TRANSMITIDO: LA VARIEDAD DE LOS RECURSOS}

Sería ilógico suponer aleatoria la selección de las imágenes reproducidas en los carteles turísticos del PNT, tanto en el caso de los autores -dibujantes o fotógrafos- como en el de las autoridades encargadas de su selección, aprobación y publicación. Estas imágenes nos permiten hoy valorar qué se consideraba atractivo para potenciar la visita a nuestro país por parte de los extranjeros - y también la visita a nuestros mejores destinos por parte de la emergente burguesía nacional - y qué lugares se consideraban más representativos para satisfacer esta condición. Con ello, se está configurando -de manera más o menos consciente - una selección de todo cuanto pueda representar mejor la esencia de nuestro país, de aquello que pueda ofrecer una imagen más envidiable de nuestro territorio y, consiguientemente, una auténtica identidad turística basada en nuestros mayores valores territoriales, entendidos estos en el más amplio de los sentidos:

A) Unos recursos físicos variados. Es fácil comprobar cómo los carteles del PNT transmiten un buen número de los rasgos físicos del territorio - clima, relieve, vegetación...-, de manera que quede bien patente la variedad que encierra el territorio español.

En cuanto a los recursos climáticos, es cierto que no tardó en comprenderse que la benignidad del clima de buena parte de España, singularmente de su litoral, resultaba envidiable para los ciudadanos de los países noratlánticos europeos, allí de donde procedía el mayor número de nuestros visitantes. Así, en la ya citada Gaceta de Madrid del 12 de mayo de 1935, al convocar un concurso de dibujos para la elaboración de carteles turísticos de España se requería que «El dibujo habrá de ser una exaltación de los atractivos climáticos de España, en su aspecto de país meridional y luminoso» y que el cartel no debería llevar más título que «Visit Sunny Spain». Las campañas publicitarias españolas empezaban a especializarse en un mensaje nítido de país cálido, luminoso, de clima agradable.

Desde algunos años antes, son varios los carteles que incidían en la benignidad del clima de ciertos lugares, especialmente de los mediterráneos: así, en un cartel sobre Levante se indica «gloriosa primavera/ España es bella todo el año»; en el de Alicante se insistía en «Donde no hay invierno. La playa de las palmeras» y en el de Málaga en que poseía «Clima delicioso en todo tiempo/ Incomparable estación de invierno», mientras en todos ellos - y también en el de Baleares, centrado en Formentor, o en el de Cádiz en las salinas - se describían escenarios de sol, aguas tranquilas y ausencia de nubes. Curiosamente, esta selección coincide con aquellos lugares que hoy constituyen los espacios clave del residencialismo de origen europeo en nuestro país.

No sólo las playas reconocidamente cálidas ofrecen esa imagen en los carteles: en Bilbao, en la Playa de El Abra, mujeres elegantes toman el sol luciendo desmangados; en Santander, se invita a veranear en un lugar dibujado bajo un sol espléndido. 
De todas formas, otro de los valores que intenta transmitirse es la variedad de climas existentes en algunos espacios próximos; así, en el caso de Granada, en un curioso cartel donde se refleja el paisaje soleado del Sacromonte y Sierra Nevada y un curioso horizonte donde se vislumbra un mar de aguas tranquilas; o en el de un Tenerife de clima amable junto a nieves perpetuas; o en otro en el que se reconocen una iglesia catalana y la nieve del Pirineo. Un curioso cartel de Casenave habla del invierno en España, con un paisaje tinerfeño entre plataneras y una montaña nevada, mientras se muestran dos rudimentarios climogramas de Málaga y Baleares (incorrectos, marcando horas de sol).

Otros carteles destacan incluso otras realidades climáticas españolas menos típicas. Así, un cartel sobre España donde se reflejan las murallas de Ávila y la ciudad bajo una nevada presume de «Una sinfonía de clima variado», u otro que invita a visitar España en cualquier época mostrando un paisaje invernal de montaña pirenáica.

La misma variedad puede observarse al analizar el relieve mostrado. Son numerosísisimos los paisajes que conjugan mar y montaña, especialmente visible en las playas norteñas - San Sabastian, Santander, las Rías Bajas, la Costa Brava... - , pero más todavía en algunos paisajes insulares, del mar agreste de las Baleares a la volcánica Tenerife. También se presume de las ciudades y pueblos en el mar, en la falda o la cumbre de una loma, como Málaga, Sitges o el Monasterio de la Rábida, en una amplia llanura convertida en un vergel marítimo (Levante) o vista al fondo de una salina, como Cádiz.

No es casual que la mayoría de las poblaciones citadas estén entre aquellas más claramente vinculadas con el tradicional veraneo cantábrico, de marcadas raíces decimonónicas, y con el emergente turismo mediterráneo que mostraba sus posibilidades en Málaga, Mallorca - favorecidas ya por el turismo de cruceros-, Alicante o Sitges. En algún caso, existen errores geográficos evidentes - caso de «Tenerife. Les îles fortunées», o «Baleares. La isla de las maravillas»-, confundiendo a su antojo isla y archipiélago. Todo valía para la publicidad.

Otras veces se presentan los paisajes agrestes de las áreas montañosas, valles entre montañas como Arán o Roncesvalles, o desfiladeros angostos, como el de Covadonga. En cualquier caso, dibujantes y fotógrafos tratan siempre de aprovechar esa perspectiva, en ocasiones majestuosa, que muestran las ciudades - singularmente las más monumentales - cuando pueden mostrarse a diferente altura. Por eso, en ciudades de interior se trata de presentar la imagen de la ciudad sobre el río que transcurre en su parte más baja, algo que puede observarse en una vista de Madrid desde el Puente de Toledo, en la propia Toledo desde su puente más característico sobre el Tajo o Salamanca volcada sobre el Tormes. Curiosamente, como ejemplo casi irrefutable, hasta Sevilla — Sevilla «la llana»aparece dibujada a diferentes alturas por Juan Miguel Sánchez.

De acuerdo con lo anterior, la vegetación y los cultivos presumen también de la amplia variedad disponible en España, muchas veces utilizada creando un contraste en el mismo cartel: chumberas y piteras en Granada, flores y chumberas en Málaga, pinos y piteras en la Costa Brava, naranjos y palmeras en Córdoba o pinos y palmeras en Huelva. Es evidente en los carteles el predominio de la vegetación más asociada al calor y la sequedad (chumberas, piteras, plataneras, palmeras...), aunque pocas veces queda remarcada como recurso esencial del cartel, con la excepción de las tierras valencianas: «Alicante: Donde no hay invierno. La playa de las palmeras», «Fleurs et fruits de la Mediterranée». 
Los carteles del norte - Bilbao, Santander, Roncesvalles, Puigcerdá- hacen alarde de sus paisajes verdes, mientras son mucho más ocasionales las arboledas fluviales - Salamanca, Segovia - las coníferas (Arán) o los jardines frondosos (Generalife). Si bien es cierto que los carteles hacen referencia a los dos parques nacionales existentes en el país - Covadonga y Ordesa, aprobados por Real decreto de 15 de agosto de 1918 - es escasa o nula la referencia a los sitios nacionales y jardines históricos que tanto promovió la II República, si bien es verdad que los carteles de esta época son menos abundantes y rara vez se trataba de lugares conocidos en el exterior.

B) Los recursos humanos: entre tradición y modernidad. Mostrar un marcado contraste entre tradición y modernidad en un mismo país fue uno de los objetivos esenciales de los carteles. La modernidad es bien patente en un gran número de detalles, desde las nuevas costumbres a las infraestructuras disponibles. En cuanto a las nuevas costumbres, destacan claramente dos rasgos bien significativos: la vestimenta de ambos sexos, pero especialmente la femenina, y la posibilidad de la práctica deportiva. Las señoritas elegantes aparecen en buen número de carteles, desde las burguesas veraneantes de las playas cantábricas, presentes en los carteles de Bilbao y Santander, a las señoritas andaluzas con tacones en la campiña gaditana, pasando por las mujeres madrileñas dibujadas por Vaquero o Penagos o las que circulan por el paseo marítimo de Alicante. En referencia a los deportes, la variedad también es notable: el polo en Puigcerdá, el montañismo en Arán, las traineras en San Sebastián o el paso de los peregrinos por Roncesvalles y Santiago.

Frente a la imagen exterior de una España atrasada, se insiste repetidamente en mostrar la modernidad a partir de determinadas infraestructuras. El automóvil se convierte en protagonista más o menos central de buen número de carteles, en un país que había realizado un enorme esfuerzo por modernizar sus carreteras durante los años de Primo de Rivera y que contaba ya con un notable parque automovilístico - 201.249 en 1929, según el Anuario Estadístico del Instituto Nacional de Estadística-, que crecía con rapidez, sobre todo en las grandes ciudades (Barcelona, Madrid, Sevilla, Valencia) y en la costa cantábrica. El coche circula por las carreteras más empinadas o zigzagueantes, como en los carteles de Covadonga y las Rías Bajas, y está presente en las playas de moda como El Abra o Santander y en algunos diversos madrileños.

A veces, modernidad y tradición se plasman en el mismo cartel, como sucede en el dedicado al parador de Gredos: desde el propio edificio del parador, recién construido pero de factura clásica y utilizando algunos materiales artísticos previos, hasta una aparente fiesta rural donde conviven caballos y automóvil. También es perceptible en el cartel de Rías Baixas, en el contraste entre el automóvil y el horreo, o en la alegoría de España de Galí, de claras referencias catalanas, donde coexisten un barco de vela y otro moderno.

Si la modernidad, incluso el cosmopolitismo (destacado explícitamente en el cartel de San Sebastián), predomina en las grandes ciudades y en el norte, los aspectos tradicionales se destacan en la España del sur. Así, en Granada - sin duda, uno de los grandes centros turísticos de la época-, con un barrio de cuevas encaladas frente al viejo palacio musulmán, o en el andaluz del parque de la mezquita cordobesa. También en los paisajes castellanos, como la mujer con alcuza y el hombre embozado que caminan junto a la catedral burgalesa, en los paisanos que penetran con un animal por la puerta de la muralla de Ávila o en los tipos ataviados con trajes típicos de Oropesa o de la fotografía de 
Andrada con el lema «Spain is different». Por supuesto, el máximo contraste con el resto, la imagen más tradicional y exótica corresponde al cartel de Marruecos, simbolizado en la vieja medina de Tetuán.

Tratar de identificar lo tradicional y peculiar con lo exótico, conjugándolo con la garantía de un confort mínimo es una idea patente en algunos carteles: «Emociones de arte e historia. Grata y fácil vida moderna», sobre un fondo de influencias catalanas; "Le confort de l'Europe, la luxuriance de l'Afrique vous attendent en Espagne», sobre otro ligado a Andalucía.

C) Un amplio abanico de artes y culturas. La variedad incluye, por supuesto, la referencia a los diferentes tipos de arte desarrollados a lo largo de los distintos momentos históricos: desde la época grecorromana (Empúries, Torre de los Escipiones de Tarragona), a la musulmana muy centrada en Andalucía (Alhambra, Generalife, Mezquita, Giralda), la románica (Santiago, pinturas murales), el gótico de castillos y catedrales - principalmente castellanas - el esplendor renacentista de El Escorial o Salamanca... hasta llegar a referencias casi recientes, inconclusas todavía en el caso de la Sagrada Familia de Gaudí, reflejada en una curiosa vista aérea del Ensanche barcelonés.

La misma variedad es perceptible en los temas tratados, que como hemos visto sólo tangencialmente podían reflejar la figura humana, con lo que era imposible encontrar alguno similar a la manola enlutada que presidía el cartel de la exposición de Londres de 1914, la que presidía el lema de «Sunny Spain» y sólo al fondo reflejaba una Granada simbolizada en la Alhambra y la Sierra Nevada (imagen 3). Ahora, las referencias humanas son secundarias, personajes que pasan a lo lejos, detalles de la escena; el mayor de todos ellos es la figura reflejada en un mural románico del cartel de Galí de 1930 o en la alegoría canaria de 1935 .

Predominan, por supuesto, las construcciones religiosas: grandes catedrales góticas, modestas iglesias en el mar catalán, referencias al pasado musulmán y a monasterios — del grandioso Escorial a la más modesta Rábida onubense - . En segundo lugar, las construcciones ligadas con el poder civil, desde palacios de cualquier época — desde la Alhambra a la moderna Magdalena santanderina-, a ciudades amuralladas y castillos (Oropesa, Alcázar...) o a la memoria de los dirigentes (torre de los Escipiones). También aparecen los lugares ligados a aspectos culturales - la Universidad de Alcalá o museos en Madrid o Valladolid - , a calles y plazas concretas - la puerta de Macarena en Sevilla, la medina de Tetuán, las plazas de Platerías en Santiago o del Cristo de los Faroles en Córdoba-, o a puentes que invitan a adentrarse en la ciudad - Toledo, Madrid - . Por supuesto, la visión general externa es seleccionada para representar algunas ciudades de gran riqueza monumental: Toledo, Cádiz, Salamanca... y algunas pequeñas poblaciones como Roncesvalles y Puigcerdá. Sólo en una ocasión, en el cartel que Antonio Moliné dedica a las Canarias (seleccionado en el concurso de 1932), se recurre a la imagen alegórica, la de una mujer entre siete islas: no sólo no es común, sino que hubiera sido desestimado según las normas planteadas para los carteles de 1929.

Por supuesto, entre los lugares seleccionados para representar la imagen turística de España abundan algunos ligados a la propia institución editora, como los paradores de Gredos y Oropesa, a buen número de monumentos ligados al patrimonio nacional y a los dos únicos parques nacionales existentes en aquel momento (Covadonga, representado en 
dos carteles, y Ordesa). No aparece, sin embargo, ninguna de las poblaciones donde se ubicaron los albergues inaugurados en la época republicana: Manzanares, Bailén, Quintanar, Almazán... (Bayón, 1999: 40). Durante los años de la II República, no se muestran motivos religiosos salvo, curiosamente en 1937, ya en periodo bélico, para denunciar las destrucciones del patrimonio religioso efectuadas por el enemigo.

\section{EL TERRITORIO TRANSMITIDO: LOS OBJETIVOS ESTRATÉGICOS}

Del análisis de conjunto de los carteles disponibles, es posible conocer cuáles fueron las líneas básicas utilizadas en los carteles para la promoción turística de España. La intención global es mucho más perceptible cuando el cartel, aunque refleje un lugar concreto, sólo habla del conjunto del país. El mejor ejemplo lo constituyen los dos carteles que utilizan como imagen el alcázar segoviano, sin que ninguno haga referencia expresa a la capital castellana; en uno, con fotografía de Lladró de 1930, se habla de un país «typical and picturesque, exuberant and delightful»; en el otro, de 1935, con dibujo de VázquezDíaz, se dice que «L'Espagne a mille visages.... en toutes saisons, vous en trouverez qui vous souriront». Es la variedad, el abanico de posibilidades, los contrastes compendiados en un único país aquello que constituyó durante todo el periodo el punto fuerte de la promoción exterior de España.

A) Una gran variedad climática. El desarrollo de este contraste en todos los aspectos vinculados a un viaje será el eje al que se vincule la promoción exterior que los carteles supusieron. Ya lo hemos visto en los aspectos climáticos, a partir de los que se alentaron las visitas en toda época: «Spain, glorious spring», con una imagen de huerta litoral valenciana, muy similar al que, con el mismo paisaje afirma que «España es bella todo el año». Hay una solución de continuidad entre el «Veranead en El Sardinero», la «Estation d'hiver» (sic) en un cartel de Sitges; o ese clima «delicioso en todo tiempo» con el que se promoció Málaga. Pero también la variedad climática en sí misma como punto fuerte, esa «sinfonía de clima variado» con la que se difunde una imagen de una Ávila gélida, o ese «Siempre vale la pena un viaje a España», acompañando a una foto del frío valle de Arán. Tal vez sea el cartel de Galí el que mejor lo compendie en un largo eslogan: «Soleil, mer, neiges éternelles, merveilles artistiques... tous les attraits du tourisme en un seul pays: l'Espagne». Aunque es cierto que en los últimos tiempos se acabó apostando decididamente por el «Sunny Spain».

También se fomentó el contraste entre la tradicional visión despectiva del «Africa empieza en los Pirineos», atribuida a A. Dumas, y el pujante avance español de los años veinte. Se presumía de esto último mientras se utilizaba una imagen española de puente entre culturas: «Emociones de arte e historia: grata y fácil vida moderna», con la Giralda al fondo y arcos de herradura en primer plano; «The Romance of the east with the comforts of the west», bajo una fotografía del Generalife. Ese destino singular que compendia todo está patente en el cartel que, con una curiosa vista superior de la catedral de León, afirma «Un Voyage en Espagne est une date dans la vie» (imagen 4).

Por supuesto, también hubo objetivos ligados a la promoción concreta de un determinado puerto como lugar de entrada de visitantes, o escala de cruceros: «Barcelona, capital del Mediterráneo», «Cádiz, puerta de Europa». 
C) Una imagen nacional de España. Los carteles no sólo transmitieron mensajes turísticos, sino que hubo otros inconfundiblemente políticos, pues no hay que olvidar que a través de ellos se transmitía una imagen de país hacia el exterior y también buscaban ofrecer una imagen amable a la propia población española, a fin de que se sintiese orgullosa de su país, de su propia pertenencia al mismo y — de forma menos perceptible, pero no menos presente- del sistema político imperante en cada momento.

En primer lugar, transmiten una imagen nacional ligada a los parámetros vigentes en aquellos años tan difíciles para Europa, precisamente por la exacerbación nacionalista. Esta imagen nacional, de recuerdo de las glorias pasadas consideradas como parte esencial de un pasado compartido, es totalmente evidente en numerosos carteles, especialmente en los de Burgos «Tierra del Cid», Huelva «Cuna de América», «Pont de depart de Christofe Colombe», «Alcalá de Henares, cuna de Cervantes», «Toledo imperial, museo de España» o «Valladolid, vieja corte de Castilla». Menos visible, pero también presente en las imágenes relacionadas con el mundo musulmán, se halla «Court des califes» en referencia a Córdoba, o «Visit le Maroc avec sa vie et types pintoresques», en un momento en que prácticamente representaban la recuperación de una imagen de potencia colonial media en un país que había perdido los restos de su viejo imperio en 1898.

Esta imagen nacionalista, de honda raíz castellana, casaba mal con la tradición catalana, por lo que no es de extrañar que Cataluña buscase un protagonismo diferente en este aspecto a través de la creación de su organismo autónomo en 1932, pese a que siempre siguió colaborando con el PNT, fomentando una cartelería propia, en distintos idiomas, con poco texto, potenciadora de sus propias comarcas y no centrada en un tipo concreto de recurso: hay lugares de sol y playa (Costa Brava, Sitges), sitios arqueológicos (Empúries) o áreas de montaña, además de apoyar a la ciudad de Barcelona en su objetivo de convertirse en puerto de cruceros o potenciar su carácter ferial (Moreno, 2007:129).

Junto a la potenciación de la imagen nacional, cada régimen político - la Monarquía alfonsina y la II República - trató de asociar indirectamente su concepción política a dicha imagen. Recordemos que el rey Alfonso XIII no siempre se ciñó al papel estrictamente representativo que se le asignaba; Fuster (1991: 282) llega a comentar que la creación del PNT está vinculada a las discrepancias del monarca con el marqués de la Vega-Inclán (presidente de la anterior Comisaría Regia), con motivo del lugar elegido para la construcción del parador de Gredos en otro distinto al que el rey, muy aficionado a la caza, prefería. Así las cosas, no es raro ese culto a la monarquía que rezuman algunos de los primeros carteles: «El Escorial: la maravilla del mediterráneo español: panteón de sus reyes»; «La imperial Toledo»; «Tumba de reyes» en referencia a León; «Madrid, centro de España y corte de sus reyes», después sustituido por «Madrid, corte y corazón de España» en un cartel posterior; «Valladolid, vieja corte de Castilla» o «Corte de los califas» en referencia a Córdoba.

En la época republicana no existe esa referencia expresa al régimen, aunque los nuevos carteles abandonan el viejo logotipo coronado del PNT. El cartel de Canarias, donde aparece ya una figura femenina, marca una diferenciación respecto a los planteamientos anteriores, pero no es fácil asociarla a ninguna de aquellas alegorías republicanas tan de moda en la época. Solo en los carteles de 1937, la defensa del régimen será absolutamente evidente, dado el momento histórico que se estaba viviendo. 
D) Una sesgada selección territorial y temática. Por otra parte, ni aparecen representadas todas las provincias españolas, ni se muestran todos los motivos habitualmente vinculados con la identidad turística posible para España. Así, no hemos podido comprobar la existencia de carteles relativos a las fiestas populares más representativas: ni la feria de abril sevillana, ni las fallas, ni los sanfermines; tampoco las corridas de toros que tan fácilmente se asocian a las tradiciones españolas, ni ese universo de manolas y contrabandistas tan ligado a la imagen que ofreció Prosper Merimée sobre nuestro país. $\mathrm{Si}$, como afirma Herrero, «la imagen de España se forjó desde los mitos románticos, por lo que resultaba casi imposible que nuestro país se desprendiera de la leyenda negra y de los estereotipos constituidos por los escritores extranjeros. Pero, la cuestión es que Europa siempre se ha sentido atraída por la España del siglo XIX. Los hombres galantes y valerosos, las mujeres seductoras y bellas y los ritos y costumbres de la España más racial son iconos que nos han acompañado e identificado durante más de un siglo» (2012: 188), poco de ello se muestra directamente en los carteles estudiados. Tampoco se presentan aquellos balnearios, casi siempre lejos de los centros urbanos, en los que la vieja burguesía decimonónica pasaba descansadas semanas; se trataba en esos años de un tipo de práctica en franca decadencia (Moreno, 2007: 24-28). Si aquellos cartelistas supieron plasmar el importante patrimonio natural e histórico cultural de nuestro país, lo hicieron en un momento en que ya se rendía culto al sol y al cuerpo, en que la práctica del deporte era un rasgo de modernidad y distinción y en que los ayuntamientos ya se preocupaban por el embellecimiento urbano y por las prácticas higienistas, por el prestigio de sus recursos culturales y económicos y por el orgullo de sus mejores épocas pasadas.

Como se indica abajo en el mapa, resulta interesante destacar que en los carteles estudiados - que, insistimos, no deben ser la totalidad de los realmente publicados - aparecen desigualmente representadas las provincias y regiones. Así, faltan cuatro de las actuales comunidades autónomas - Aragón, Extremadura, La Rioja y Murcia-. Tampoco aparecen las provincias de Álava, Albacete, Almería, Castellón, Ciudad Real, Cuenca, Guadalajara, Jaén, Las Palmas, Lugo, Orense, Palencia, Soria y Zamora, además de Ceuta y Melilla. Y al contrario, hemos recogido siete sobre Madrid y tres sobre la provincia de Girona, aunque éstos proceden de la Oficina de Turisme. Cuando el cartel sólo indica el nombre del país, y no el del lugar representado, a pesar de que resulte fácil reconocerlo, se utilizan el Alcázar de Segovia (en dos ocasiones), el paisaje valenciano (en otras dos), Sevilla con la Giralda al fondo, la plaza cordobesa del Cristo de los Faroles, los jardines del Generalife, la catedral de León, las murallas de Ávila y algunos paisajes de montaña (desde el Pirineo a Canarias).

Prácticamente, no se presenta nunca la obra emprendida por la Comisaría Regia, salvo el parador de Gredos, inaugurado ya por el PNT; ni la Casa de los Tiros, ni el rehabilitado barrio de Santa Cruz; antes bien, se muestra la puerta de la Macarena, en el lado opuesto de la Sevilla histórica. Ya hemos visto que sólo se promociona en cartel una reducida parte de los lugares donde el propio PNT había emprendido inversiones. Sí están todas aquellas ciudades en las que se concentraba la mayoría de visitas de los extranjeros que llegaron a España en aquellas fechas: Granada, Córdoba, Málaga, San Sebastián, Palma de Mallorca... y, por supuesto, Madrid y Barcelona. Sólo hallamos una excepción, Zaragoza, de la que no hemos encontrado cartel alguno pese a tratarse de uno de los grandes destinos, aunque con claro predominio de los visitantes nacionales. 


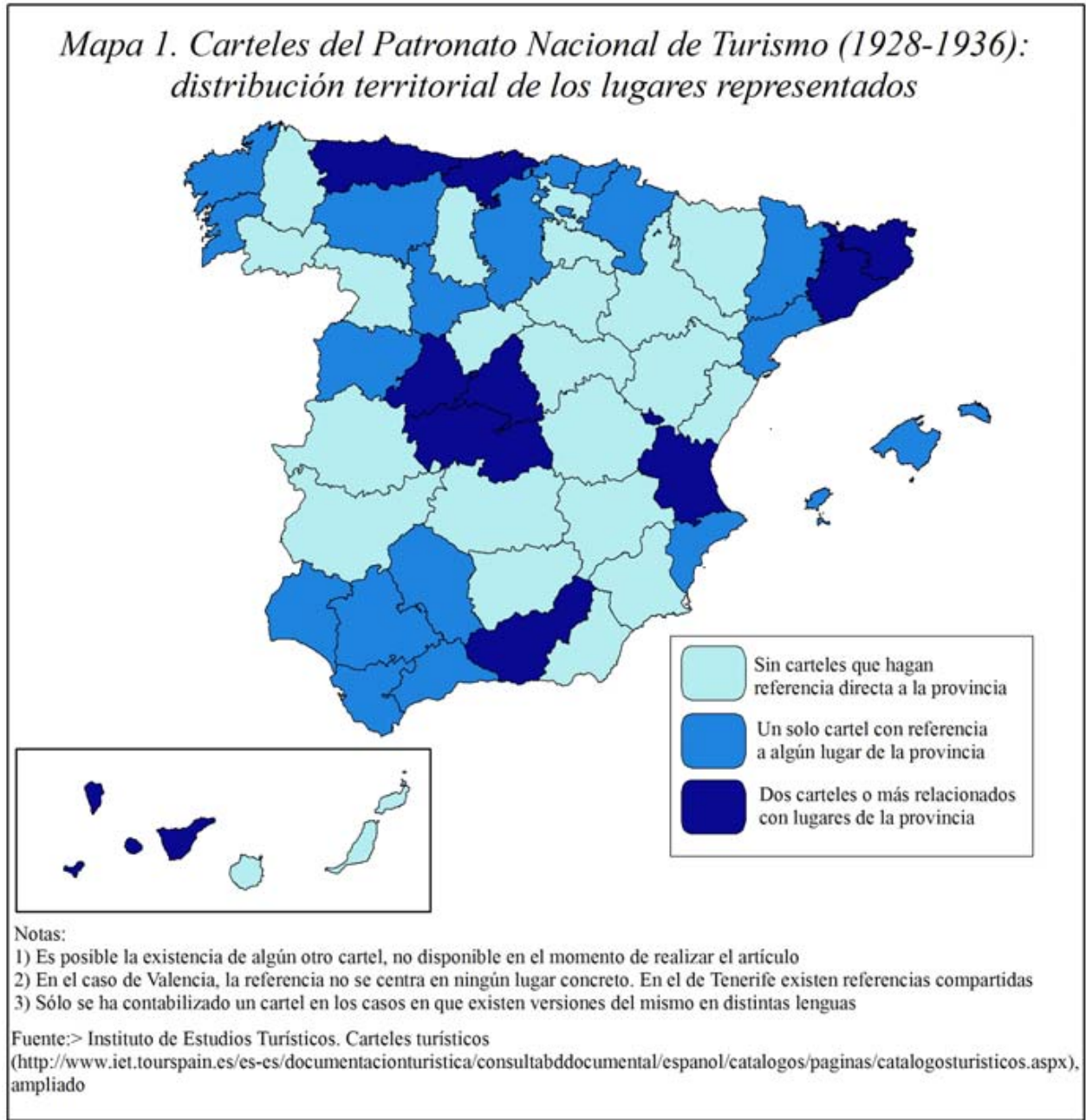

Está claro que en la promoción turística pesaron los intereses económicos de aquellas ciudades que habían asumido décadas atrás una apuesta cada vez más fuerte por el turismo como factor de desarrollo. El artículo de La Vanguardia ya citado se titulaba significativamente «El turismo, artículo de primera necesidad». También pesaron, sin duda, los intereses económicos de la industria gráfica española, cuyo peso creció significativamente en las primeras décadas de siglo (Carreras, 2005: 367): Madrid y Barcelona concentraron el grueso de los pedidos, especialmente los talleres cromolitográficos de la primera - sobre todo, Talleres La Voluntad en los inicios - en el caso de los dibujos, y los de fotografía de la segunda en cuanto a esta clase de carteles. Los talleres catalanes también coparon el grueso de las ediciones promovidas desde la Oficina de Turisme de la Generalitat. Hay que señalar, no obstante, que en la época republicana, se produjo 
una cierta descentralización: Artes Gráficas de Gijón, Imprenta Ortega de Valencia o la Unión Gráfica de Tolosa son algunos ejemplos. Cabe recordar que el primer cartel publicado, el relativo a las exposiciones internacionales, fue impreso en La Grande Firme de París. En la medida de sus posibilidades, pues, el PNT también promovió el desarrollo de la industria nacional.

E) Una promoción innovadora. Los carteles del PNT fueron especialmente innovadores en algunos aspectos que sólo han sido retomados muchas décadas después. Por ejemplo, en el turismo urbano más allá de los aspectos estrictamente culturales y monumentales, como se percibe en el cartel de Colde Guezala sobre la playa bilbaína de El Abra, o en el de dibujo de «Madrid. Temporada de primavera», de Baldrich. Otro aspecto importante fue la creciente apuesta por los litorales cálidos, frente a las viejas temporadas de balnearios o el predominio de las playas cantábricas, culminada con la exigencia del «Sunny Spain» como única referencia en la convocatoria de carteles de 1935. También es destacable la referencia reiterada en aquellos lugares más relacionados con el Camino de Santiago en un momento en que el peregrinaje compostelano era absolutamente minoritario: hay constancia directa en los carteles de Santiago y de Roncesvalles - punto de comienzo del camino francés en España - y atención a dos de los principales hitos del mismo itinerario, la catedral de Burgos y la de León. Además, en este último cartel, en su versión en que no aparece el nombre de la ciudad, la inscripción «Un Voyage en Espagne est une date dans la vie» supone una concepción entonces innovadora de la actividad turística, la que se centra en la propia experiencia vital del viajero, el viaje como parte del desarrollo personal.

\section{CONCLUSIONES}

La cartelería editada por el Patronato Nacional de Turismo, y el propio organismo, nace en un contexto histórico preciso con un objetivo claro: tratar de fomentar, a corto plazo, las visitas a las próximas exposiciones internacionales de Sevilla y Barcelona, que debían inaugurarse un año después; más allá de esa necesidad concreta, y apoyándose también en ambos eventos, se trataba de presentar al país como uno más entre los estados florecientes del continente europeo, destacando el proceso de modernización vivido en España en las dos últimas décadas, con una mejora evidente de las infraestructuras, un notable desarrollo industrial y un evidente crecimiento de las grandes ciudades.

Esa imagen de una España moderna, alejada de la visión peyorativa sólidamente asentada en algunos países europeos, contó con una más que estimable colaboración de los grandes cartelistas españoles de la época, que supieron transmitir una visión de una España multiforme, variada, eterna y renovada, aunque predominasen los estilos artísticos más conservadores y, al tiempo, tan distantes de esa gran innovación plástica que estaban impulsando, entre otros, algunos grandes pintores españoles. Si para el primer cartel de la colección aún se recurre al exterior, en el encargo de dibujos para la exposición de Sevilla se pudo comprobar claramente el enorme potencial artístico nacional.

Los principales dibujantes que concurrieron partían de concepciones artísticas marcadamente diferentes en ocasiones, desde algunas ligadas al Art Decó a otras con influencias cubistas o impresionistas, como es fácil comprobar en autores como Penagos, Vázquez- 
Díaz, Morell o Baldrich. Varios de ellos participaron, desde ambos bandos, durante la Guerra Civil en el desarrollo de una cartelería muy diferente a la que nos ocupa, que gozó y sigue gozando de una excepcional repercusión internacional; así, el comunista Josep Renau, el carlista Sáez de Tejada o el gallegista Castelao se han convertio en auténticos iconos de concepciones del mundo contrapuestas.

Buscando el alejamiento de aquella España simbolizada en la Carmen de Merimée, de bandoleros de Sierra Morena y toreros en busca de fortuna, desaparecen las clásicas manolas con abanicos y flores en el pelo, que todavía protagonizaron carteles tan conocidos como el del V Congreso Internacional de Turismo de Madrid, en 1912, o el de la exposición de Earl's Court en Londres, en 1914.

Aquellos cartelistas fueron capaces, no sólo de transmitir los recursos patrimoniales de todo tipo - monumentos, paisajes, climas... - de los que podía presumir el país, sino también de mostrar un país intensamente variado, orgulloso de un pasado genuino y de una modernidad que se abría paso a un ritmo acelerado.

Además, analizados en su conjunto, supieron generar y transmitir una identidad turística nacional sólida, basada en la diversidad complementaria, ligando tradición y modernidad, asociando el sentido de aventura que despierta lo exótico y la seguridad que ofrecen las comodidades de la sociedad de consumo, incorporando, tal vez de forma inconsciente, aspectos innovadores como el concepto de ciudad museo -explícito en el cartel toledano, pero también perceptible en otros casos-, el viaje como experiencia vital o guiños a un turismo urbano que va más allá de lo estrictamente monumental. Aparece también, a partir de algunos carteles de Levante (las tierras valencianas, pero no sólo ellas), un mundo ligado al sol y al mar, donde las ciudades no se perciben y que sienta las bases para la imagen que poco después atraería a nuestras playas a millones de turistas.

Cuando en la época republicana se exija como requisito el texto de «Visit Sunny Spain» a quienes se presenten al concurso de dibujos para el Patronato, o se publique la fotografía de Andrada sobre el lema «Spain is different», es evidente que se habían establecido ya las bases de lo que serían las líneas básicas de la promoción turística de los años sesenta.

\section{BIBLIOGRAFÍA}

AGUIRRE GONZALO, J.M. (1979): «Una visión anticipada de la alternativa turística», El País, 28-10-1979.

ALCOCER, J.A. (1991): El mundo del cartel, Madrid, Ediciones Granada.

ALCARAZ, E., HUGUES, B. y CAMPOS, M.Á. (1999): Diccionario de términos de marketing, publicidad y medios de comunicación, Barcelona, Ariel referencia.

ANDRÉS DEL CAMPO, S. (2002): «Asignatura, contenido editorial y empresa. La publicidad en los preludios de la guerra civil», Publifilia Revista de Culturas Publicitarias, $\mathrm{n}^{\circ}$ 6, pp. 19-36.

BAYÓN MARINÉ, F. (dir.) (1999): 50 años del turismo español. Un análisis histórico y estructural, Editorial Centro de Estudios Ramón Areces, S.A.- Escuela Oficial de Turismo.

BORI, R. y GARDÓ, J. (1928): Manual práctico de publicidad, Barcelona, Cultura. 
CARRERAS, A. y TAFUNELL, X. (2005): Estadísticas Históricas de España, Bilbao, Fundación BBVA.

CAL, R. (1997): «La propaganda del turismo en España. Primeras organizaciones», Historia y Comunicación Social, $\mathrm{n}^{\mathrm{o}} 2$, pp. 125-133.

CENTRO DE DOCUMENTACIÓN TURÍSTICA DE ESPAÑA (2000): Catálogo de carteles oficiales de turismo del Centro de Documentación Turística de España. Dos volúmenes: tomo I (1957 a 1979); tomo II (1980 a 2000) Madrid, Centro de Publicaciones del Ministerio de Economía y Hacienda.

CENTRO DE DOCUMENTACIÓN TURÍSTICA DE ESPAÑA (2005): Catálogo de carteles oficiales de turismo. 1929-1959, Madrid, Instituto De Estudios Turísticos.

CIVIT, X. et alter (2003): Imatge i destí: cartells turístics de les comarques gironines, Girona, Museo de arte de Girona, Dirección general de Turismo.

CORONADO, D. (2001): La metáfora del espejo: teoría e historia del cartel publicitario, Sevilla, Alfar.

CORREYERO, B., CAL, R. (2008): Turismo: la mayor propaganda del Estado. España: desde sus inicios hasta 1951, Madrid, Visión Libros.

DONAIRE J.A. y GALÍ, N. (2012): «Eslóganes turísticos: un análisis de los eslóganes de los destinos catalanes», Boletín de la Asociación de Geógrafos Españoles, nº 60, pp. 521-533.

FELIU, E. (1984): Los lenguajes de la publicidad, Alicante, Universidad de Alicante.

FERNÁNDEZ FUSTER, L. (1991): Historia general del turismo de masas, Madrid, Alianza Universidad Textos.

FERNÁNDEZ POYATOS, M.D. (2011): «La publicidad de la salud en la prensa ilustrada del siglo XIX», Questiones Publicitarias, 2011, vol. I, n 16, pp. 103-119.

FERRER, E. (1994): El lenguaje de la publicidad, México, Fondo de Cultura Económica.

GACETA DE MADRID, LA, 27 de junio de 1932, nº 179, p. 2191.

GACETA DE MADRID, LA, 12 de mayo de 1935, n 132, p. 1288.

GARRIDO, M. (2000): «El eslogan del año 2000», Questiones Publicitarias, nº 8, pp. 68-87.

GARRIDO, M., REY, J. y RAMOS, M. (2012): «Evolución y desarrollo del eslogan publicitario: tercer análisis», Pensar la publicidad, $\mathrm{n}^{\circ} 2$, pp. 407-426.

GUBERN, R. (1997) Medios icónicos de masas, Madrid, Historia 16.

HERRERO, R. (2012): «El cartel como instrumento de promoción en los inicios del turismo español (1900-1936)», V Jornadas de investigación en turismo. Turismo y sostenibilidad, Sevilla, Edición Digital@tres S.L., pp. 173-198.

KLENOSKY, D.B. y GITELSON, R.E. (1997): «Characteristics of Effective Tourism Promotion Slogans», Annals of Tourism Research, 24 (1), pp. 235-238.

MORENO GARRIDO, A. (2007): Historia del turismo en España en el siglo XX, Madrid, Editorial Síntesis.

MORENO GARRIDO, A. (2010): «El Patronato Nacional de Turismo (1928-1932). Balance económico de una política turística», Investigaciones de Historia Económica, pp. 103-134.

MORENO GARRIDO, A. (2012): «Historia del turismo: una investigación necesaria», V Jornadas de Investigación en Turismo, Sevilla, Edición Digital@tres, S.L.pp. 105-126. 
ORTEGA, E., MORA, P. y RAULD, L. (2006): «El eslogan en el sector turístico español», Cuadernos de turismo, $\mathrm{n}^{\circ}$ 17, pp. 127-146.

PATRONATO NACIONAL DE TURISMO (1930): Memoria de los trabajos realizados por el Patronato Nacional de Turismo desde julio de 1928 a 31 de diciembre de 1929, Madrid, Talleres Voluntad.

PELLEJERO MARTÍNEZ, C. (2002): «La política turística en la España del siglo XX: Una visión general», Historia contemporánea, $\mathrm{n}^{\circ}$ 25, pp. 233-265.

PÉNINOU, G. (1976): Semiótica de la publicidad, Barcelona, Gustavo Gili.

PEÑA PÉREZ, G. (2001): «El valor persuasivo del eslogan publicitario», Círculo de Lingüística Aplicada a la Comunicación (CLAC), nº 6, pp. 85-95.

PIKE, S. (2004): «Destination brand positioning slogans - towards the development of a set of accountability criteria», Acta Turística, no 16 (2): 102-124.

PRAT GABALLI, P. (1934) Publicidad Racional, Barcelona, Labor.

R.E. (¿Rafael de Eulate?) (1935): «El turismo, artículo de $1^{\mathrm{a}}$ necesidad. Algunos defectos, enormemente importantes en suma, que conviene desterrar», La Vanguardia, 5-1-1935.

REBOUL, O. (1978): El poder del slogan, Valencia, Fernando Torres Ed.

SANZ DE LA TAJADA, L.A. (1974): «Los problemas de la comunicación desde el lado de los receptores», Comunicación XXI, n ${ }^{\circ}$ 8, pp. 10-11.

VIDAL, D., MONTURIOL, A. (2011): Exposició 75 aniversari de Oficina de Turisme a Catalunya, Direcció General de Turismo, Barcelona, Departament d'Innovació, Universitats i Empresa de la Generalitat de Catalunya. Universitats i Empresa de la Generalitat de Catalunya. Barcelona. http://www.gencat.cat/diue/doc/doc_23099700_1.pdf. Consultado 12/12/2013. 


\section{ANEXO IMÁGENES}

\section{Imagen 1}

CARTEL DEL PATRONATO NACIONAL DE TURISMO CON FOTOGRAFÍA DE FRANCISCO ANDRADA ESCRIBANO, DE 1935, DONDE SE REPRESENTA UN GRUPO ATAVIADO CON TRAJES TÍPICOS CASTELLANOS.

EL LEMA YA ES SPAIN IS DIFFERENT

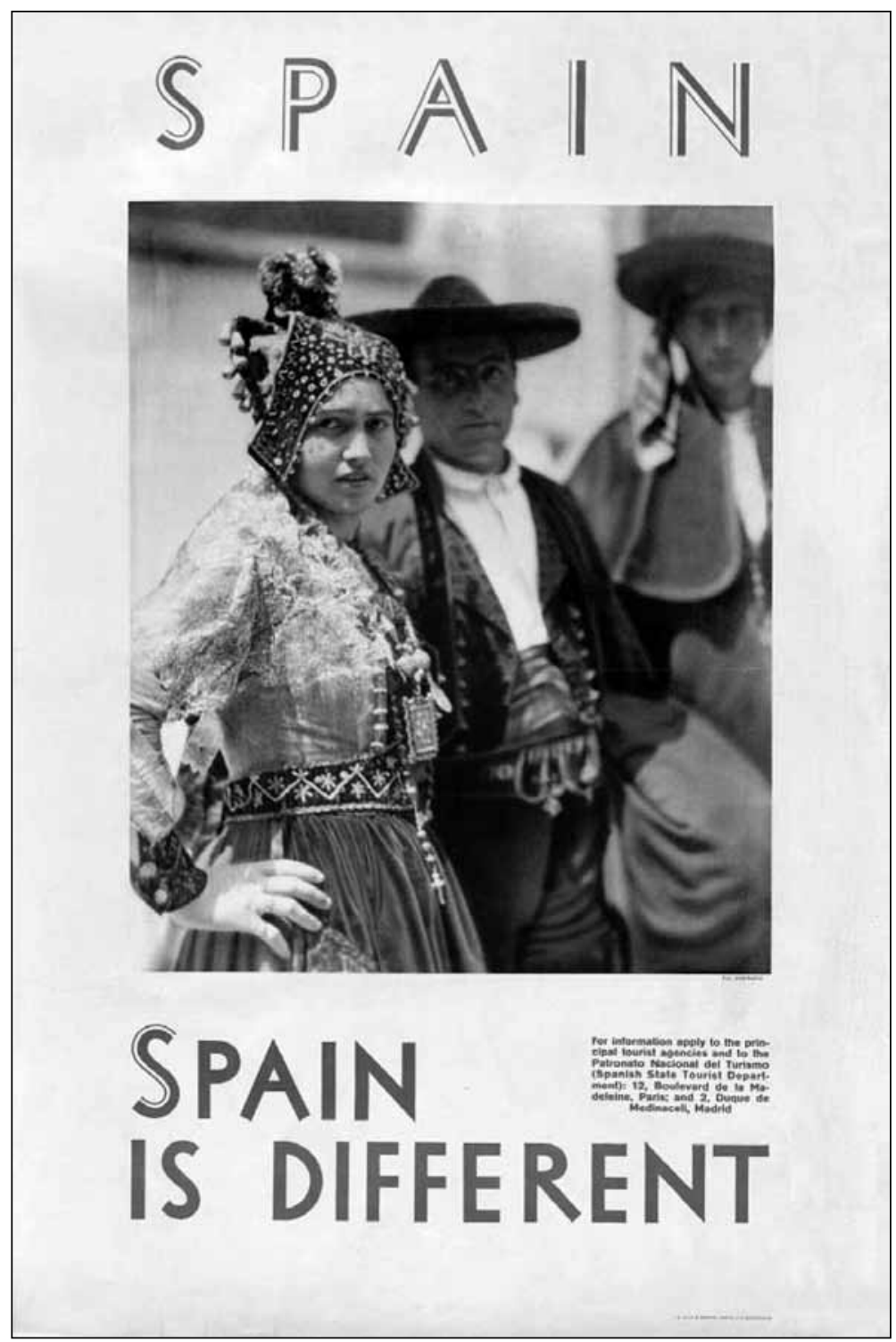

Consultado el 19-8-2013 en http://cartellistes.blogspot.com.es/2013_05_01_archive.html 


\section{Imagen 2}

CARTEL DE JOSEP MORELL PARA EL PATRONATO NACIONAL DE TURISMO A MEDIADOS DE LOS AÑOS TREINTA. QUIEN SERÍA EL MÁS RECONOCIDO CARTELISTA DE TURISMO DE LA ESPAÑA DE POSGUERRA, YA COLABORABA EN ESTAS TAREAS ANTES DE LA GUERRA CIVIL

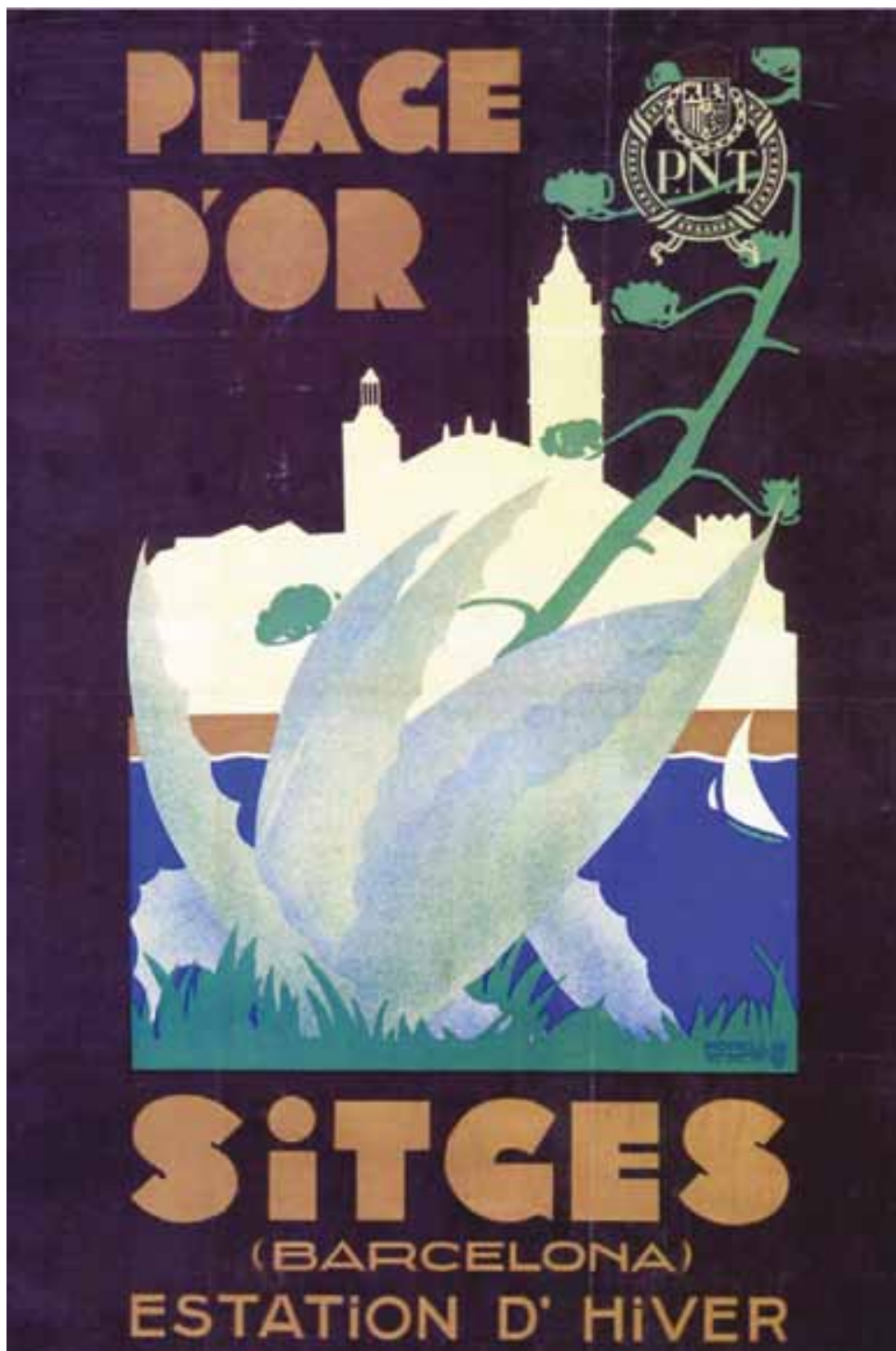

Fuente: Instituto de Estudios Turísticos. Catálogo de carteles, http://www.iet.tourspain.es/img-iet/Carteles/30-06. JPG. 


\section{Imagen 3}

CARTEL ANUNCIADOR DE LA EXPOSICIÓN QUE LA COMISIÓN REGIA DE TURISMO IBA A CELEBRAR EN EARLS COURT, EN LONDRES EN 1914. EL LEMA YA HACE REFERENCIA AL CARÁCTER SOLEADO DEL PAÍS: SUNNY SPAIN

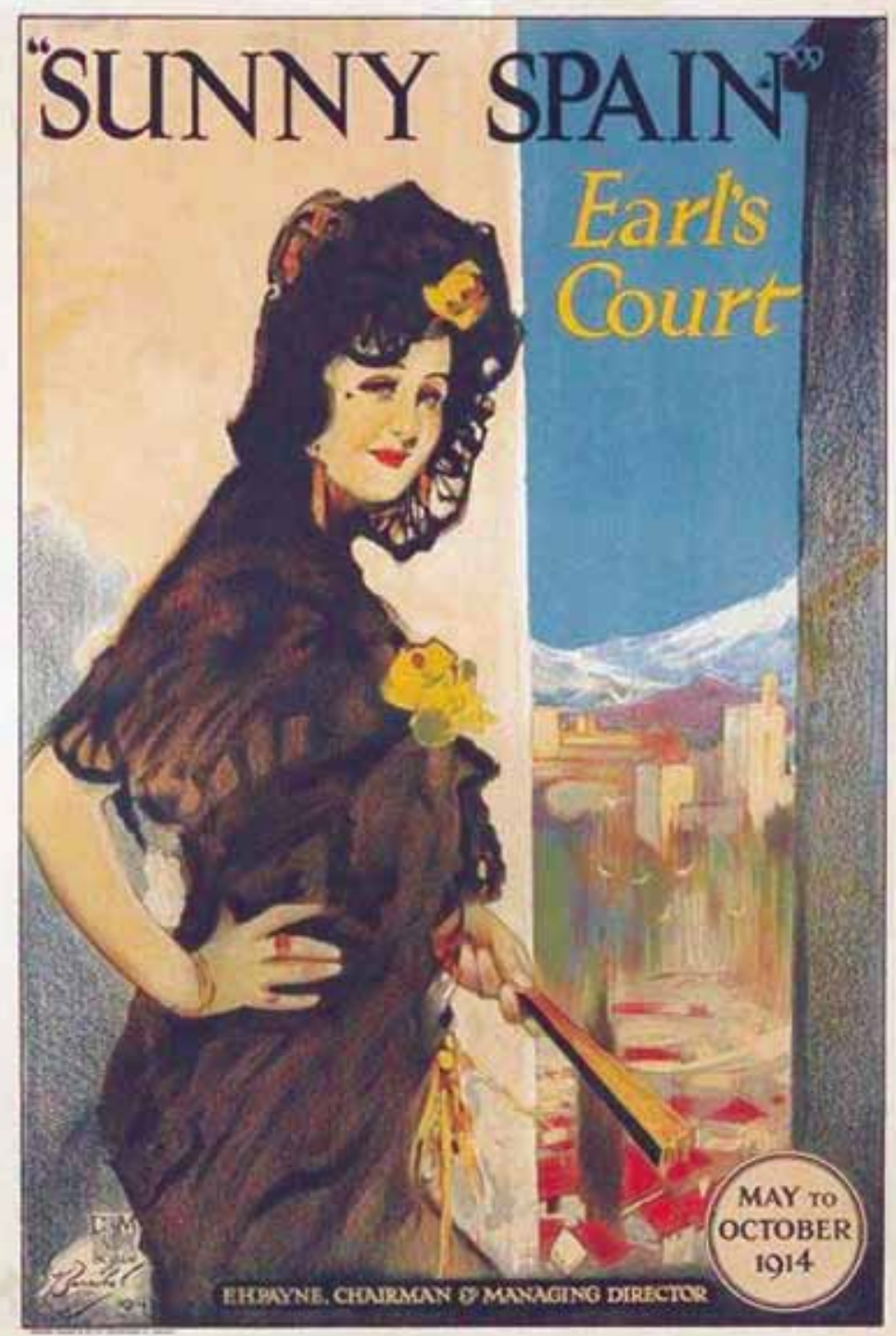

Durante la redacción del artículo sólo nos ha sido posible acceder a él a través de algunas páginas de Internet, como: www.artvalue.com/auctionresult--barribal-william-h-act-1919-19-sunny-spain-earl-s-court-2726012.htm. 
Imagen 4

CARTEL DE HIPÓLITO HIDALGO DE CAVIEDES PARA EL PATRONATO NACIONAL DE TURISMO, DE 1930. FRENTE A LA VERSIÓN EN ESPAÑOL, QUE HABLABA DE LEÓN COMO TUMBA DE REYES, LA VERSIÓN EN FRANCÉS REPRESENTA UNA NOVEDOSA VISIÓN DEL TURISMO COMO EXPERIENCIA VITAL

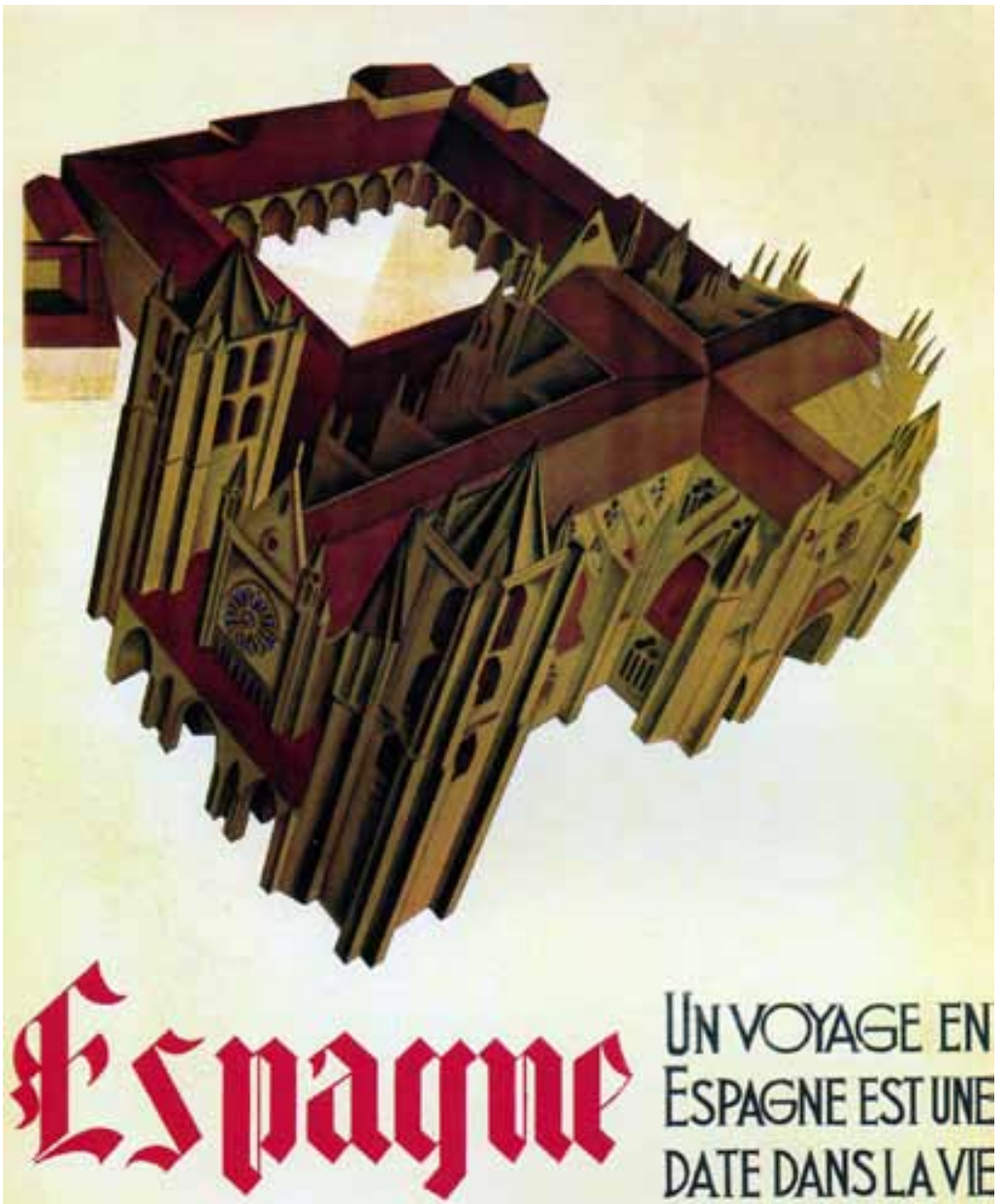

Information gratuitet Patronato Naolonal del Turismo. (OHllo Natlonal Espagnol du Tourisme) Madrid: Medinacell, 2; Paris: 12, Boulevard de la Madeleine. Informations et bllletset Dans toutes les Agences de Voyages.

Fuente: Instituto de Estudios Turísticos. Catálogo de carteles, http://www.iet.tourspain.es/img-iet/Carteles/30-07. JPG. 